\title{
Dimethyloxalyglycine stimulates the early stages of gastrointestinal repair processes through VEGF-dependent mechanisms
}

\author{
Tania Marchbank ${ }^{1,2}$, Asif Mahmood ${ }^{3}$, Sarah Harten ${ }^{4}$, Patrick H Maxwell ${ }^{5}$ and Raymond J Playford
}

Dimethyloxalylglycine (DMOG) is an inhibitor of prolyl-4-hydroxylase domain enzymes. Its potential value and mechanism of actions in preventing/treating gastrointestinal injury are, however, poorly understood. We, therefore, examined the effect of DMOG on influencing gut injury and repair using a variety of in vitro and in vivo models. We performed in vitro studies utilising pro-migratory (wounded monolayer) and proliferation (using DNA quantitation) assays of human stomach (AGS) and colonic (HT29) carcinoma cells. Time course studies examined changes in hypoxia-inducible factor (HIF) and vascular endothelial growth factor (VEGF) levels, a growth factor known to be regulated via HIF. In vivo studies utilised a rat gastric (indomethacin, $20 \mathrm{mg} / \mathrm{kg}$ and $3 \mathrm{~h}$ restraint) damage model. DMOG stimulated migration in a dosedependent manner, increasing migration twofold when added at $25 \mu \mathrm{M}(P<0.01)$. Additive effects were seen when DMOG was added to cells in hypoxic conditions. DMOG stimulated proliferation dose dependently, increasing proliferation threefold when added at $70 \mu \mathrm{M}(P<0.01)$. DMOG caused upregulation of both HIF and VEGF within $4 \mathrm{~h}$ of administration. Addition of VEGF neutralising antibody truncated migratory and proliferative activity of DMOG by about $70 \%$. Both oral and subcutaneous administration of DMOG decreased gastric injury without influencing intragastric $\mathrm{pH}(50 \%$ reduction in injury when $1 \mathrm{ml}$ gavaged at $0.57 \mathrm{mM}, P<0.01)$. Indomethacin reduced tissue HIF and VEGF levels but this was prevented if DMOG was present. In conclusion, DMOG stimulates the early phases of gut repair and VEGF-dependent processes appear relevant. Non-peptide factors such as this may be useful to stabilise or repair gut mucosa.

Laboratory Investigation (2011) 91, 1684-1694; doi:10.1038/labinvest.2011.129; published online 29 August 2011

KEYWORDS: gastric damage model; hypoxia-inducible factor; restitution

The gastrointestinal tract possesses the remarkable ability to digest food without digesting itself. This is especially relevant in the stomach, which is bathed in acid, proteolytic enzymes and exposed to toxic agents such as aspirin and alcohol.

When a mucosal breach occurs, it is normally rapidly healed by a defined series of processes involving cell migration of surviving cells to re-establish epithelial continuity (a process termed restitution), followed $24 \mathrm{~h}$ later by an increase in cell proliferation to re-establish cell numbers. The mechanisms by which such systems are stimulated are, however, complex and poorly understood.

Ischaemia and associated hypoxia is thought to be pathologically relevant for several chronic and acute gastro- intestinal conditions, such as inflammatory bowel disease ${ }^{1}$ and NSAID $^{2}$ gut injury. Pharmacological manipulation of regulatory elements involved in hypoxic responses within gut tissue is, therefore, of potential clinical interest.

One of the best-known pathways of relevance to the normal hypoxic response is that of hypoxia-inducible factor (HIF), which can increase erythropesis, angiogenesis and metabolism in response to lowered oxygen tension. Dimethyloxalylglycine (DMOG), is an ester of $\mathrm{N}$-oxalylglycine that penetrates cells readily, inhibits all prolyl-4hydroxylase domain 1-3 factor-inhibiting HIF enzymes. ${ }^{3,4}$ These enzymes are known as oxygen sensors and determine the stability and activity of the hypoxia-inducible

\footnotetext{
${ }^{1}$ Faculty of Health Science, University of Tasmania, Hobart, TAS, Australia; ${ }^{2}$ Blizard Institute of Cell and Molecular Science, Digestive Diseases, Barts and the London School of Medicine, Queen Mary University of London, London, UK; ${ }^{3}$ Department of Gastroenterology, Epsom and St Helier NHS Trust, Carshalton, Surrey, UK; ${ }^{4}$ Department of Nephrology, Imperial College School of Medicine, Hammersmith Hospital, London, UK and ${ }^{5}$ Division of Medicine, University College London, London, UK Correspondence: Professor RJ Playford, FRCP, FMedSci, Office of the Dean, Faculty of Health Science, University of Tasmania, Medical Science 1, 17 Liverpool Street, Hobart, Tasmania 7000, Australia.

E-mail: raymond.playford@utas.edu.au

Received 26 January 2011; revised 6 July 2011; accepted 27 July 2011
} 
transcription factors. ${ }^{5}$ However, recent studies suggest that the hydroxylase inhibitory activity of DMOG has a much wider portfolio of influence including actions on the inflammatory cascade, nuclear factor $\kappa \mathrm{B}(\mathrm{NF} \kappa \mathrm{B})$ production, ${ }^{6}$ sensitivity to tumour necrosis factor- $\alpha$ signalling and possibly mediating stimulating angiogenesis. ${ }^{4,6}$

In view of these activities, the value of chronic administration of DMOG has been tested and shown of potential benefit for cerebral ${ }^{7}$ and limb ischaemia. ${ }^{8}$ DMOG has also been shown to reduce inflammatory markers in dextran sodium sulphate-induced colitis in mice and much of its activity in this model was, therefore, attributed to immune modulation. ${ }^{6}$

However, the influence of DMOG on the early stages of gut repair are unknown. We, therefore, examined if DMOG can influence the early stages of the repair process using a variety of in vitro and in vivo models. The dependence of any effects seen on the growth factor, vascular endothelial growth factor (VEGF), pathways were also examined as DMOG has been reported to upregulate VEGF production. ${ }^{9,10}$

\section{MATERIALS AND METHODS}

All chemicals were obtained from Sigma (Poole, Dorset, UK) unless otherwise stated. DMOG $\left(\mathrm{C}_{6} \mathrm{H}_{9} \mathrm{NO}_{5}\right.$, MW 175) was obtained from AXXORA (UK), Nottingham, UK.

\section{Ethics}

All animal experiments were approved by the Local Animals Ethics Committee and covered by the appropriate licences under the Home Office Animals Procedures Acts, 1986.

\section{Study Series A: Effect of DMOG on In Vitro Models of Repair \\ Background to methods}

One of the earliest repair responses following injury to tissue is the migration of surviving cells over any denuded area to re-establish epithelial integrity. Since it is difficult to study this effect inside a human or animal, cell culture models are commonly used as surrogate markers of this pro-migratory response.

1. Cell migration as a model of wound repair: Cell migration assays were performed using our previously published methods. ${ }^{11}$ Briefly, human stomach (AGS) and colonic (HT29) carcinoma cells were grown to confluence in six-well plates containing medium (Hams F12 for AGS cells, DMEM for HT29 cells) plus $10 \%$ fetal calf serum (FCS) at $37^{\circ} \mathrm{C}$ in $5 \% \mathrm{CO}_{2}$. Cells were then serum starved for $24 \mathrm{~h}$. The monolayers were then wounded by scraping a disposable pipette tip across the dishes, washed twice with fresh serum-free medium.

The rate of movement of the anterior edges of the wounded monolayers was then determined by taking serial photomicrographs at various times after wounding. ${ }^{11}$ An inverted microscope (Nikon TS100) and a Nikon Coolpix 800 digital camera with 125 -fold magnification was used to obtain photomicrographs. Identical regions were examined at each time point by pre-marking the base of the plates to facilitate alignment. Twenty measurements per field were performed by placing a transparent grid over the photograph and measuring the distance moved from the original wound line.

\section{Main Study: Effect of DMOG}

Cells were treated as above and cultured in serum-free medium in the presence of various concentrations of DMOG (6.25-75 $\mu \mathrm{M})$.

All results are expressed as the mean (s.e.m.) of triplicate wells.

Additional monolayers containing DMOG at $25 \mu \mathrm{M}$ had the proliferation inhibitor, mitomycin $\mathrm{C}(5 \mu \mathrm{g} / \mathrm{ml})$, or an anti-transforming growth factor- $\beta$ (TGF $\beta$ ) antibody (100 $\mu \mathrm{g} /$ $\mathrm{ml}$; R\&D Systems Europe, Abingdon, $\mathrm{UK}^{9}$ ), added and examined in the same way to determine whether restitution responses were proliferation or TGF $\beta$ dependent.

The influence of hypoxia \pm DMOG on the rate of cell migration was also examined by incubating wells with medium alone or DMOG $(25 \mu \mathrm{M})$ under normoxic $(21 \%$ $\left.\mathrm{O}_{2}\right)$ or hypoxic $\left(1.5 \% \mathrm{O}_{2}\right)$ conditions. For this experiment, only the zero and $24 \mathrm{~h}$ time point were assessed (as we did not wish to keep exposing the cells in hypoxic conditions to reoxygenation while the photomicrographs were being taken).

To investigate the importance of VEGF in the promigratory effect of DMOG, cells were incubated with medium alone, DMOG $(25 \mu \mathrm{M})$ or recombinant human VEGF $_{165}(10 \mathrm{ng} / \mathrm{ml}, 293$-VE; R\&D Systems Europe $) \pm$ VEGF neutralising antibody $(1 \mu \mathrm{g} / \mathrm{ml}$, MAB293; R\&D Systems Europe).

2. Cell proliferation: Cell proliferation assays utilised a commercial CyQUANT cell proliferation assay (Invitrogen, Paisley, $\mathrm{UK}^{12}$ ). This method follows changes in the amount of DNA as a marker of changes in cell number. We also performed identical studies utilising Alamar blue (Invitrogen ${ }^{13,14}$ ), this assay incorporates a specially selected oxidation-reduction indicator that undergoes colorimetric change in response to cellular metabolic reduction. Both assays were performed as per the manufacturer's instructions measuring changes in either fluorescence (excitation $485 \mathrm{~nm}$, emission $530 \mathrm{~nm}$ for DNA analyses) or absorbance ( $570 \mathrm{~nm}$ for Alamar blue).

Briefly, HT29 or AGS cells were seeded at 2000 cells/well and grown in medium containing 10\% FCS in 96-well plates overnight. The following day, cells were washed twice with serum-free medium and then incubated in serum-free medium alone or also containing DMOG $(10-120 \mu \mathrm{M})$ or epidermal growth factor (EGF; positive control). Cells incubated in serum-free medium alone were used as a negative control.

To investigate the importance of VEGF in the proproliferative effects of DMOG, cells were incubated with medium alone or also containing DMOG $(70 \mu \mathrm{M})$ or recombinant human VEGF $_{165}(10 \mathrm{ng} / \mathrm{ml}, 293-\mathrm{VE} ; \mathrm{R} \& \mathrm{D}$ 
Systems Europe $\left.{ }^{9}\right) \pm$ VEGF neutralising antibody $(1 \mu \mathrm{g} / \mathrm{ml}$, MAB293; R\&D Systems Europe).

3. Time course examining effect of DMOG administration in vitro on HIF and VEGF expression: To examine whether the administration of DMOG at the doses used in the in vitro studies influenced HIF and VEGF expression, AGS or HT29 cells were cultured in the relevant medium containing $10 \%$ FCS with or without $25 \mu \mathrm{M}$ DMOG for $0,4,8,12$ and $24 \mathrm{~h}$. At the end of the incubation period, cells were washed in ice-cold PBS, lysed in lysis buffer $(20 \mathrm{mM}$ Tris- $\mathrm{HCl}, 5 \mathrm{mM}$ EDTA, $150 \mathrm{mM} \mathrm{NaCl}$ and protease inhibitor cocktail (P8340) $\mathrm{pH}$ 7.4) for $5 \mathrm{~min}$ on ice. Lysates were cleared by centrifugation at $10000 \mathrm{~g}$ for $10 \mathrm{~min}$ at $4^{\circ} \mathrm{C}$. Protein concentrations were determined using a standard BCA method (Pierce, Rockford, IL, USA). HIF1 $\alpha$ and VEGF concentration in the supernatant and lysates was determined using Duoset Elisa kits as per the manufacturer's instructions (DYC1935-2 and DY293B, respectively; R\&D Systems Europe). In all, $250 \mu \mathrm{g}$ of protein was used in triplicate wells for each treatment.

\section{Study Series B: Effect of the DMOG on In Vivo Models of Repair}

Although cell culture studies provide valuable information regarding potential bioactivity, additional information may also be gained by extending studies to the in vivo situation. The ability of DMOG to reduce gastric damage was, therefore, assessed using a well-validated model. ${ }^{15}$

1. Pilot study to examine changes in injury, HIF and VEGF in response to restraint and/or indomethacin: Methods used were similar to those described previously. ${ }^{15}$ Briefly, male Sprague-Dawley rats (225-275g; Harlan Olac, UK) were housed in standard cages and fed standard laboratory chow (Special Diet Services, Essex, UK) and tap water ad libitum.

Four groups of animals were studied. All rats (6-8 per group) received $1 \mathrm{ml}$ gavage containing $2 \%$ hydroxymethylpropylcellulose to delay gastric emptying (to reflect conditions used for study 2), plus sc injections of indomethacin or saline.

1. No indomethacin, no restraint

2. No indomethacin, restraint for $3 \mathrm{~h}$

3. Indomethacin $(20 \mathrm{mg} / \mathrm{kg})$ but no restraint

4. indomethacin $(20 \mathrm{mg} / \mathrm{kg})$ and $3 \mathrm{~h}$ restraint.

Using standard techniques, western blots were performed and probed using VEGF (147) (1/100, Santa Cruz Biotechnology, Heidelberg, Germany, sc-507) or HIF1 $\alpha$ (H-206) $(1 / 100)$ (Santa Cruz, sc-10790) and all blots were probed using $\beta$-actin (1/200, Santa Cruz, sc-130657) for standardisation. All three are rabbit polyclonal antibodies that can detect the specific rat protein as primary antibody, a secondary goat anti-rabbit IgG HRP-conjugated antibody $(1 / 5000$, Santa Cruz, sc-2004) and visualised by ECL. Films were quantitated using a densitometer using the $\beta$-actin signal as a loading control for standardisation.
These studies showed that only the animals that had received indomethacin and restraint had consistent injury (Figure 1a) and it was only in this group that significant changes in HIF $1 \alpha$ and VEGF levels were seen (Figure $1 \mathrm{~b}$ and c). Based on these results, the full study focussed on the effect of DMOG on animals that has received the combination of indomethacin and restraint.
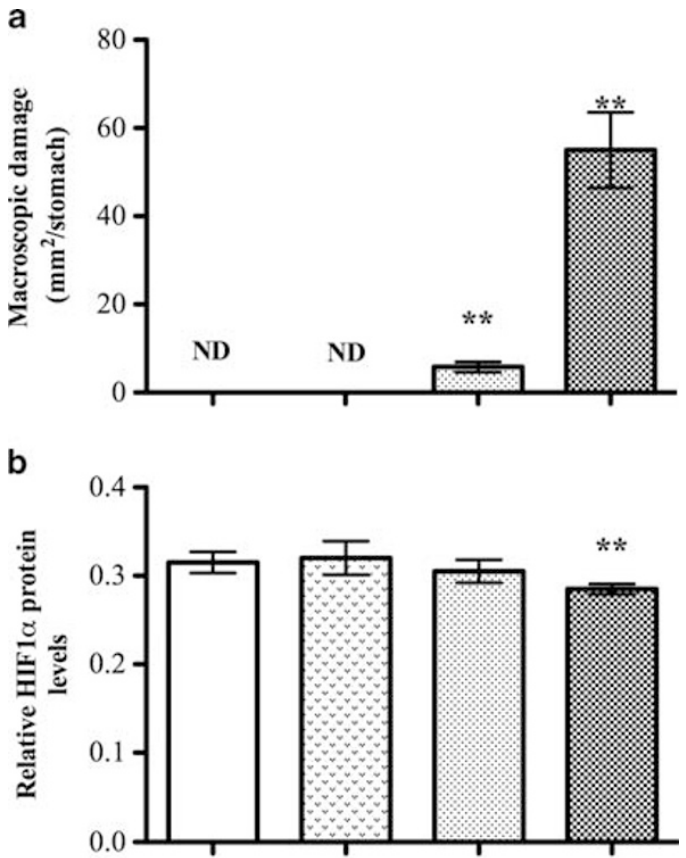

C

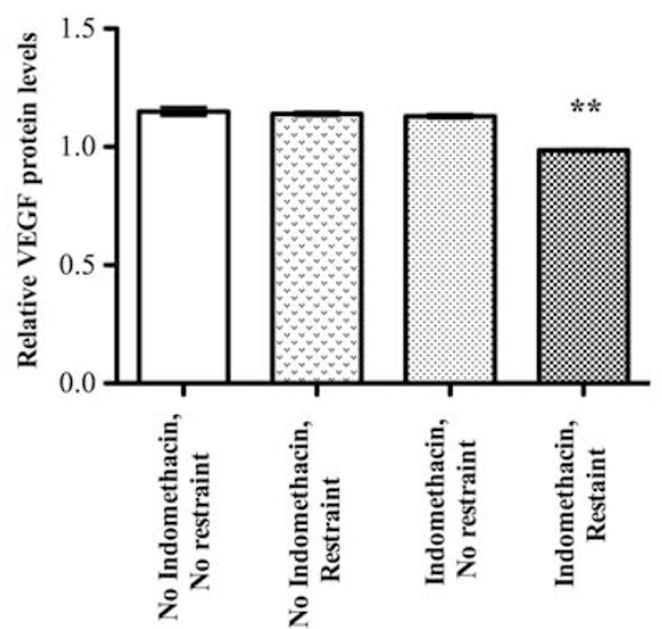

Figure 1 Pilot study: effect of indomethacin and/or restraint on injury, HIF and VEGF. All rats (6-8 per group) received $1 \mathrm{ml}$ gavage containing $2 \%$ hydroxymethyl-propylcellulose to delay gastric emptying, plus sc injections of indomethacin or saline with or without restraint. At the end of the study, animals were killed and the amount of macroscopic $\left(\mathrm{mm}^{2} / \mathrm{stomach}\right)$ damage was determined (a). HIF1 $\alpha$ (b) and VEGF (c) levels were measured in the stomachs of animals by western blot and densitometry, levels are relative to $\beta$-actin loading control. Data are presented as mean \pm s.d., ${ }^{*} P<0.001$ vs no indomethacin/no restraint. ND, not detectable. 
2. Effect of the DMOG on rat gastric damage model: Having shown that significant injury is only seen when restraint and indomethacin are used together, a second study was performed to examine the effect of DMOG on injury under these conditions. All rats (6-8 per group) received $1 \mathrm{ml}$ gavage plus $1 \mathrm{ml}$ of intraperitoneal injections. All gavage solutions also contained $2 \%$ hydroxymethyl-propylcellulose to delay gastric emptying.

The various groups comprised

1. i.p. saline + gavage saline (negative control)

2. i.p. saline + gavage DMOG $0.57 \mathrm{mM}$

3. i.p. saline + gavage DMOG $1.7 \mathrm{mM}$

4. i.p. DMOG $(0.17 \mathrm{mM})+$ gavage saline

5. i.p. DMOG $(0.57 \mathrm{mM})+$ gavage saline

6. i.p. DMOG $(2.85 \mathrm{mM})+$ gavage saline

7. i.p. EGF $(0.8 \mu \mathrm{M})+$ gavage saline (positive control)

8. i.p. saline + gavage EGF $(3.8 \mu \mathrm{M})$ (positive control).

One hour after gavage and i.p. injection, all rats received indomethacin $(20 \mathrm{mg} / \mathrm{kg}$ subcutaneously) and were placed in Bollman-type restraint cages. Three hours after indomethacin administration, animals were killed by stunning and cervical dislocation. The stomach was removed and the intragastric $\mathrm{pH}$ was determined using a micro-pH electrode and the stomach was then inflated with $4 \mathrm{ml}$ of $10 \%$ neutral buffered formalin. The next day, the stomachs were opened and placed in fresh formalin before assessment. The stomachs were randomly coded and all analyses of gastric damage were assessed blind.

Macroscopic injury was assessed using a dissecting microscope $(\times 10)$ with the aid of a reference square grid. The stomachs were then embedded in wax and the depth of damage assessed microscopically, as previously described. ${ }^{15}$ Using this system each stomach was given a score from 0 to 4 where $0=$ no damage, $1=$ one small erosion $(<0.5 \mathrm{~mm})$, $2=$ two small or one large erosion $(>0.5 \mathrm{~mm}), 3=$ two or more large erosions and $4=$ any area of ulceration extending to the muscularis mucosa.

3. Time course examining effect of DMOG administration on HIF1 $\alpha$ and VEGF expression in the in vivo model of gastric injury:

Background: Study B2 showed beneficial effects of DMOG when it was administered $4 \mathrm{~h}$ before the rats were killed. We decided to investigate if changes in HIF1 $\alpha$ or VEGF occurred during this time period as a potential mechanism. We were also aware that other groups have examined changes in HIF and VEGF after $24 \mathrm{~h}$ exposure to DMOG. However, our damaging model is only permitted for use up to $4 \mathrm{~h}$. We, therefore, added an additional group, which involved a $24-\mathrm{h}$ DMOG exposure (to determine if we found results similar to previous published work) but this group could not receive indomethacin or restraint.

Protocol: All rats (6-8 per group) received $1 \mathrm{ml}$ of intraperitoneal injections. All gavage solutions also contained $2 \%$ hydroxymethyl-propylcellulose to delay gastric emptying.
The various groups comprised

1. i.p. saline (negative control, $4 \mathrm{~h}$ before kill) + indomethacin and restraint.

2. i.p. DMOG $(2.85 \mathrm{mM})+$ indomethacin and restraint.

3. i.p. DMOG $(2.85 \mathrm{mM}, 4 \mathrm{~h}$ before kill $)+$ no indomethacin or restraint

4. i.p. DMOG $(2.85 \mathrm{mM}, 24 \mathrm{~h}$ before kill $)+$ no indomethacin or restraint

5. No treatment control animals.

One hour after i.p. injection, rats (groups 1 and 2) received indomethacin $(20 \mathrm{mg} / \mathrm{kg}$ subcutaneously) and were placed in Bollman-type restraint cages (unless stated). Three hours after indomethacin administration (groups 1 and 2) or at time stated following DMOG administration (groups 3 and 4), animals were killed by stunning and cervical dislocation. The stomach was removed and collected into RNAlater (Applied Biosystems, Warrington, UK). Samples were stored in RNAlater until use.

Determination of mRNA and protein levels for HIF $1 \alpha$ and VEGF Samples were stored in RNAlater until use. The tissue was blotted dry, placed in Trizol (Invitrogen) and homogenised using a hand-held glass homogeniser. RNA and protein were extracted from these samples as per the manufacturer's instructions. RNA concentration and purity was determined using a Nanodrop. Protein concentration was determined using a Pierce BCA kit.

\section{Real-time quantitative polymerase chain reaction}

Using standard techniques, $30 \mu \mathrm{g}$ of RNA was DNAse treated and reverse transcribed using a first-stand cDNA synthesis kit (Invitrogen) as per the manufacturer's instructions. Amplification and relative quantification of mRNA expression levels was performed using validated and optimised Quantitect primer assay pairs from Qiagen (Crawley, UK) for rat $\beta$-actin (QT00193473), rat VEGF (QT00198954) and rat HIF1 $\alpha$ (QT00182532). Reaction mixtures were set up to a final volume of $20 \mu \mathrm{l}$ using a total of $100 \mathrm{ng}$ cDNA, $20 \mathrm{pmol}$ of each primer and $10 \mu \mathrm{l}$ SYBR Green PCR Master mix (Qiagen). Amplification was performed using a RotorGene (Corbett Research/Qiagen) at least three times with independent cDNA samples and in triplicates for each cDNA and primer pair. The polymerase chain reaction protocol comprised an initial hold step of $95^{\circ} \mathrm{C}$ for $15 \mathrm{~min}$ followed by 45 cycles of amplification. The conditions were denaturation at $95^{\circ} \mathrm{C}$ for $15 \mathrm{~s}$, annealing at $56^{\circ} \mathrm{C}$ for $30 \mathrm{~s}$ and elongation at $72^{\circ} \mathrm{C}$ for $60 \mathrm{~s}$. The comparative threshold method was used for relative quantification ( $\Delta \Delta \mathrm{CT}$ method), where the amount of target was normalised to the housekeeping gene $(\beta$-actin).

\section{Western blot studies}

Stomachs were analysed using western blotting and densitometry as per study B1. 


\section{Statistics}

All values are expressed as the mean \pm s.e.m., unless stated. One- or two-way ANOVA was used as appropriate. Where a significant effect was seen $(P<0.05)$, individual comparisons were performed using $t$-tests based on the group means, residual and degrees of freedom obtained from the ANOVA, a method equivalent to repeated measures analyses.

\section{RESULTS}

\section{Study Series A: Effect of DMOG on In Vitro Models of Repair}

1. Cell migration: Addition of DMOG to AGS or HT29 cells produced increased cell migration (Figure 2) in a dosedependent manner (Figure $3 \mathrm{a}$ and $\mathrm{b}$ ). Maximal promigratory effects were seen when DMOG was added at a final concentration of $25 \mu \mathrm{M}$, resulting in a twofold increase in the rate of migration. Addition of higher doses of DMOG did not increase migration further (Figure $3 a$ and $b$ ) and at the highest doses tested, the efficiency of its pro-stimulatory activity began to reduce (bell-shaped curve).

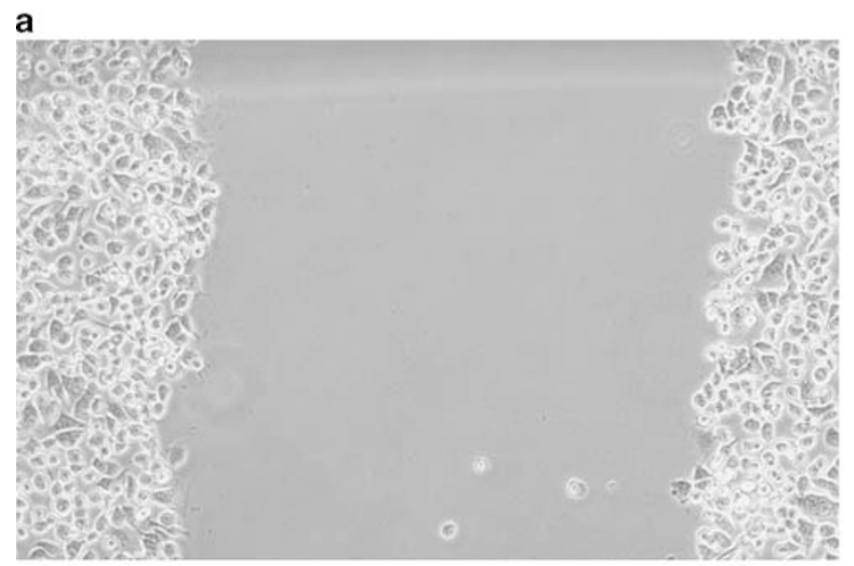

0 hour medium alone

C

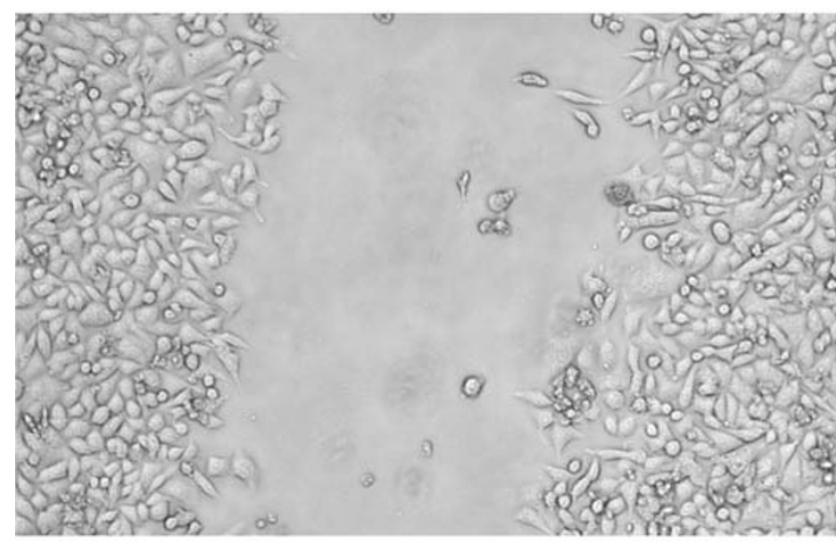

24 hour medium alone
To examine the reproducibility of the pro-migratory effect of DMOG, an additional study was performed assessing the equivalent of eight separate experiments (each in triplicate for each condition), performed on the same day. Wells contained either medium alone or also optimum dose of DMOG $(25 \mu \mathrm{M})$. The intraday co-efficient of variation using distance migrated after $24 \mathrm{~h}$ was determined as $3.7 \%$ for monolayers incubated in medium alone and $1.7 \%$ for cells incubated in DMOG.

Addition of recombinant VEGF alone $(0.5 \mu \mathrm{M})$ caused pro-migratory activity to a similar level to that of DMOG (Figure 3c). Co-presence of a VEGF neutralising antibody truncated the pro-migratory effects of recombinant VEGF or DMOG by 77 and $67 \%$, respectively (Figure $3 c$ ). In contrast, the pro-migratory activity of DMOG was not influenced by the presence of the anti-TGF- $\beta$ antibody (Figure 3d) or the proliferation inhibitor mitomycin $\mathrm{C}$ (Figure $3 \mathrm{~d}$ ).

Compared with normoxic conditions, incubating the wounded monolayers in hypoxic conditions $(1.5 \%)$ resulted in an increased rate of wound closure. Additive effects on migration were seen with hypoxia if DMOG was also present

b

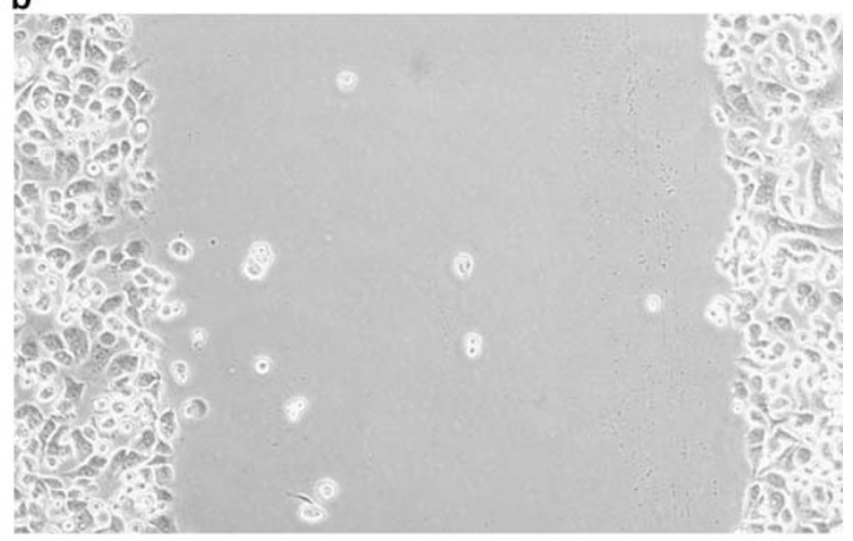

0 hour 25 uM DMOG

d

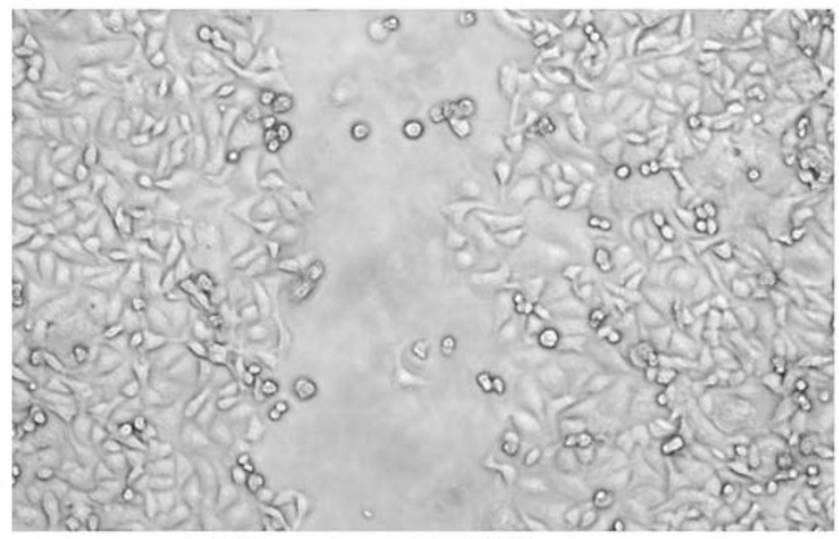

24 hours 25 MM DMOG

Figure 2 Representative photomicrographs of a cell migration assay. Monolayers of human gastric AGS cells had a standard wound inflicted at time 0 (a, b). Serial photomicrographs were taken. After $24 \mathrm{~h}$, the presence of DMOG in the medium had increased the rate of closure (compare $\mathbf{c}$, d). 



Figure 3 Effect of DMOG on wound healing as assessed by cell migration of human gastric AGS cells. Serial photographs, taken at various time points $(0-24 \mathrm{~h}$ ), were analysed for movement of the leading edge following a standard wound in AGS cells (a) and HT29 cells (b) - Negative control (DMEM alone), DMOG at $6.25 \mu \mathrm{M}(\square), 12.5 \mu \mathrm{M}(\bigcirc), 25 \mu \mathrm{M}(\mathbf{\square}), 50 \mu \mathrm{M}(\diamond) . P<0.01$ vs negative control for all time points and doses after $4 \mathrm{~h}(75 \mu \mathrm{M}$ results not shown on this graph to aid interpretation). (c) Same experiment as panel a showing only the 24-h time point data as bar graph. (d) The addition of VEGF neutralising antibody resulted in a significant reduction in DMOG $(25 \mu \mathrm{M})$ - and VEGF $(0.5 \mu \mathrm{M})$-induced stimulation of cell migration. (e) The pro-migratory effect of DMOG $(25 \mu \mathrm{M})$ was not influenced by co-presence of a TGF $\beta$ neutralising antibody $(100 \mu \mathrm{g} / \mathrm{ml})$ or the proliferation inhibitor, mitomycin C $(5 \mu \mathrm{g} / \mathrm{ml})$. ${ }^{* * P}<0.001$ vs medium alone (negative) control, ${ }^{\$ \$} P<0.001$ vs equivalent conditions without VEGF neutralising antibody (for panel c). HT29 cells gave similar results (Supplementary Figure S1).

(Figure 4a). Hypoxic conditions also increased HIF1 $\alpha$ (Figure 4b) and VEGF (Figure 4c) levels in the cells and similar additive effects were seen if DMOG was also present.

2. Cell proliferation: DMOG induced a dose-dependent 'bell-shaped curve' increase in proliferation in AGS or HT29 cells with maximal response seen at a concentration of $70 \mu \mathrm{M}$ (Figure 5a). Addition of recombinant VEGF alone to HT29 cells also caused a significant increase in proliferation
(Figure 5b). The co-presence of the VEGF neutralising antibody reduced the pro-proliferative activity of VEGF and DMOG by 51 and $60 \%$, respectively (Figure $5 b$ ).

3. Time course examining effect of DMOG administration in vitro on HIF and VEGF expression: Cells incubated under control situation showed a progressive rise in HIF and VEGF over time. This became significant at 12 and $24 \mathrm{~h}$ for HIF and VEGF, respectively (Figure 6). 
a

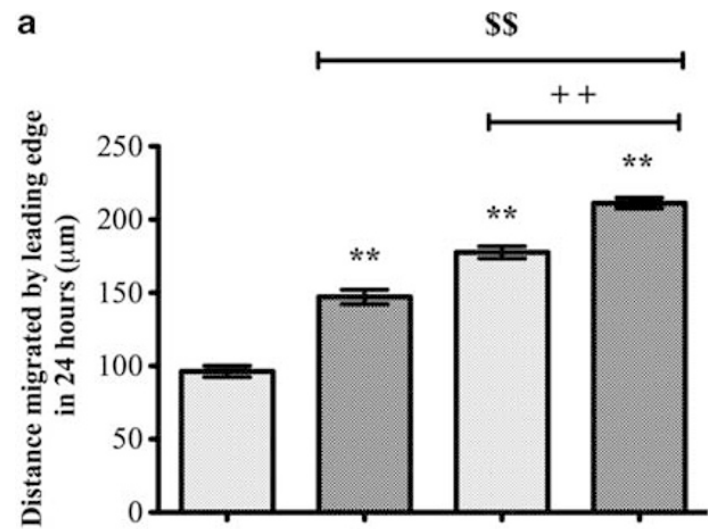

b



C

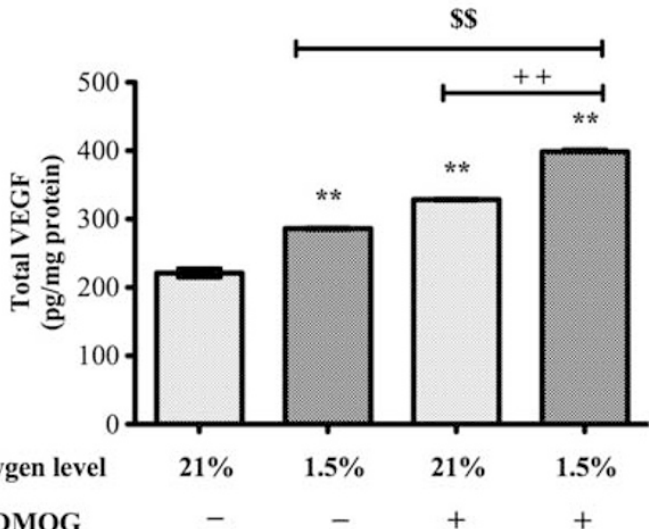

DMOG

Figure 4 Effect of hypoxia with and without DMOG on cell migration, HIF and VEGF. Wounded monolayers of AGS cells were incubated with medium alone or medium containing DMOG $(25 \mu \mathrm{M})$ under normal oxygen ( $21 \%$, 'normoxic') or $1.5 \% \mathrm{O}_{2}$ (hypoxic) conditions for $24 \mathrm{~h}$ and the distance migrated assessed (a). Cell lysates were collected and protein levels of HIF (b) and VEGF (c) were determined by ELISA. ${ }^{* *} P<0.001$ vs medium alone under normoxic conditions, respectively. ${ }^{\$ \$} P<0.001$ vs medium alone under hypoxic conditions and ${ }^{++} P<0.001$ vs DMOG under normoxic conditions. HT29 cells gave similar results (Supplementary Figure S2).

Compared with the relevant time point control of cells incubated in medium (with FCS), cells that also had DMOG present at $25 \mu \mathrm{M}$ (the concentration shown to have maximal effects on migration) showed significant increase in HIF and VEGF protein levels by the 4 -h time point. This change increased progressively at each time point studied $(4,8,12$, $24 \mathrm{~h}$ after addition).

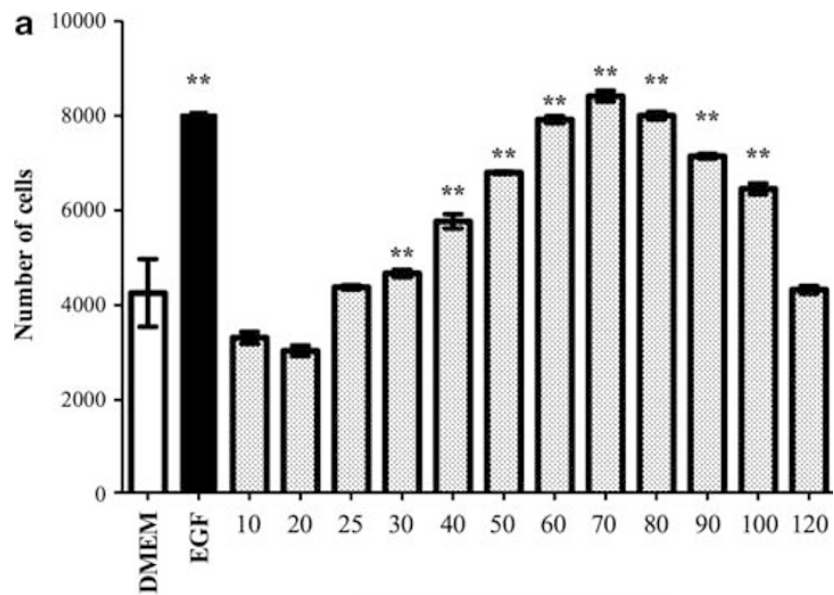

DMOG Concentration $(\mu \mathrm{M})$

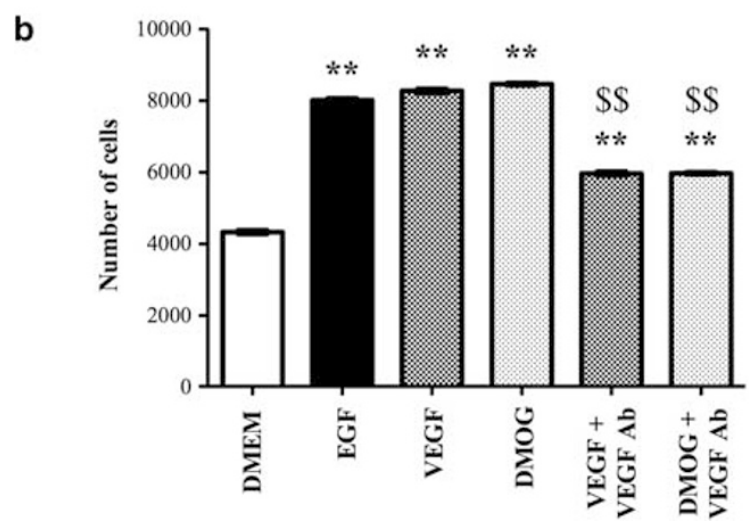

Figure 5 Effect of DMOG on proliferation of AGS cells. Amount of proliferation was determined using a CyQUANT cell proliferation assay measuring changes in fluorescence (excitation $485 \mathrm{~nm}$, emission $530 \mathrm{~nm}$ ). (a) Cells were incubated with medium alone (negative control), EGF $(1.5 \mu \mathrm{M})$ as positive control or various doses of DMOG $(10-120 \mu \mathrm{M})$. (b) Influence of the presence of recombinant VEGF, DMOG \pm a VEGF neutralising antibody was determined under similar conditions to panel a. Data are shown as mean \pm s.d. ${ }^{* *} P<0.001$ vs DMEM (negative) control, ${ }^{\$} P<0.001$ vs equivalent conditions without VEGF neutralising antibody. HT29 cells gave similar results (Supplementary Figure S3).

\section{Study Series B: Effect of DMOG on In Vivo Models of Repair} Effect of the DMOG on rat gastric damage model

Control animals had a mean macroscopic gastric damage score of $65 \pm 10 \mathrm{~mm}^{2} /$ stomach. Administration of DMOG by either the gavage or intraperitoneal route caused a dosedependent reduction in the amount of macroscopic damage (Figures 7 and 8). This equated to about a $60 \%$ reduction in injury when administered at $0.57 \mathrm{mM}$ via either route (Figures $7 \mathrm{a}$ and $\mathrm{b}$ ) and by $72 \%$ when administered at $2.85 \mathrm{mM}$ i.p. (Figure 7a). Similar results were seen when assessed using microscopic injury score (data not shown).

Administration of DMOG at a concentration of $0.57 \mathrm{mM}$ or more, gave a gastric protective effect, which was greater than that seen in animals that had received the potent 
a

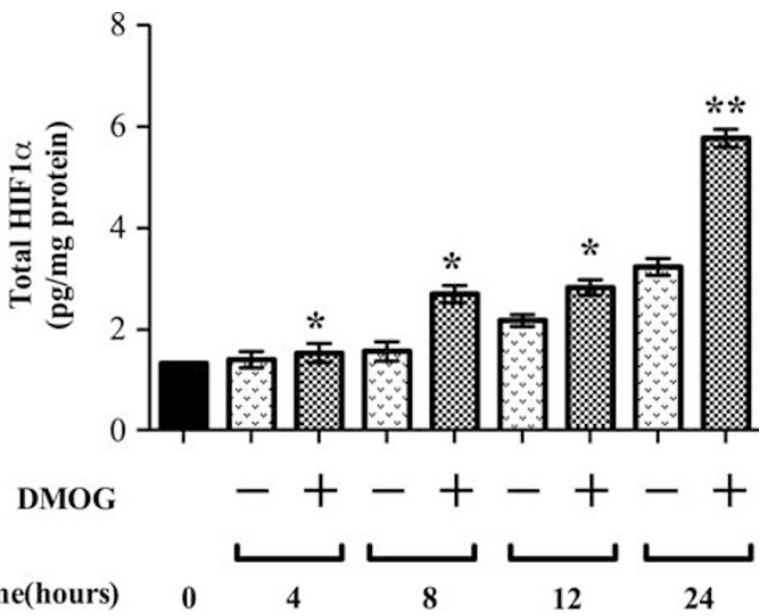

b

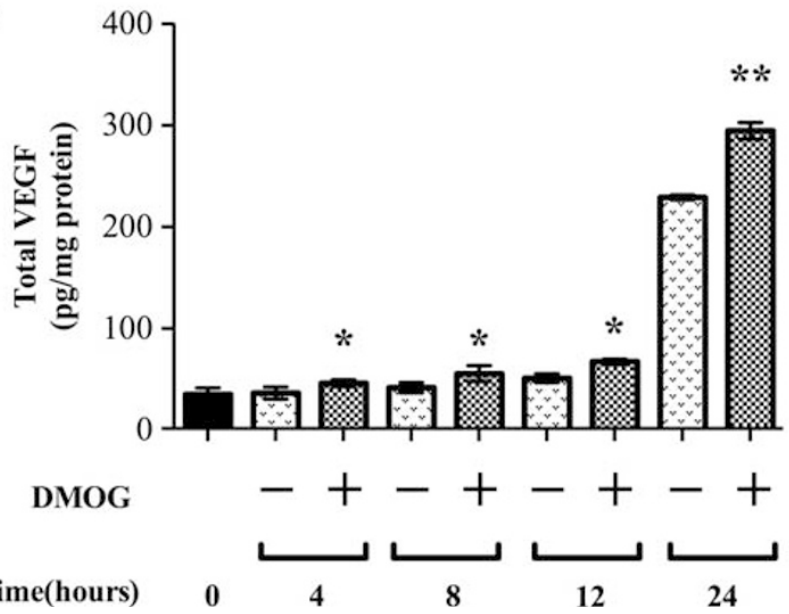

Figure 6 Effect of DMOG administration on HIF and VEGF expression. Cells were incubated for various periods in the presence and absence of DMOG $(25 \mu \mathrm{M})$. Changes in HIF $\alpha$ (a) or VEGF (b) protein levels were determined using specific ELISAs. Data are shown as mean \pm s.d. ${ }^{\star} P<0.05$ and ${ }^{*} P<0.01$ vs equivalent time without DMOG.

cytoprotective agent, EGF at $0.8 \mu \mathrm{M}$ (intraperitoneally; Figure $7 \mathrm{a}$ ) or $3.8 \mu \mathrm{M}$ (intragastric; Figure $7 \mathrm{~b}$ ).

Gastric $\mathrm{pH}$ assessment showed that all these effects were independent of alteration in $\mathrm{pH}$ (all gastric $\mathrm{pH}$ 's were in the range of 1-3).

2. Effect of DMOG on HIF1 $\alpha$ and VEGF protein and RNA expression levels in rat gastric damage model: Animals that had received DMOG in the absence of indomethacin or restraint showed no significant change in HIF $1 \alpha$ mRNA or protein after $4 \mathrm{~h}$ but both significantly rose $24 \mathrm{~h}$ after addition. Similar results were seen for VEGF except that mRNA levels had increased by $4 \mathrm{~h}$ after administration.

Animals that underwent restraint plus indomethacin administration (but no DMOG) had significant reductions in HIF and VEGF mRNA and protein levels (Figure 9). However, if DMOG was also administered before the indomethacin and restraint, this truncated the reductions in both HIF and VEGF mRNA and protein (Figure 9).
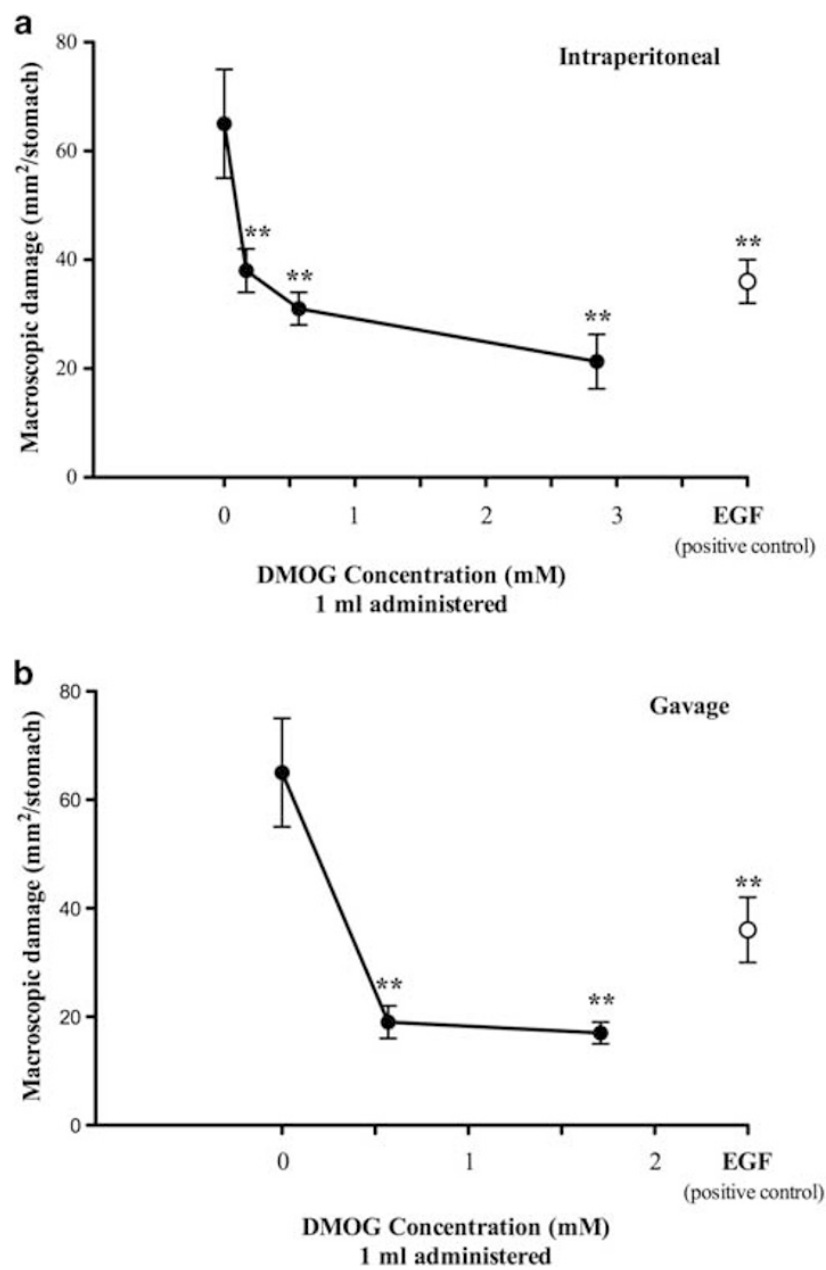

Figure 7 Effect of DMOG on rat gastric damage. All rats $(n=6-8)$ received oral gavage $(1 \mathrm{ml})$ and an intraperitoneal injection $(1 \mathrm{ml})$. Constituents of gavage and injection were saline (negative control), EGF (positive control) or DMOG. Various doses of DMOG were administered i.p. in panel a or via gavage in panel $\mathbf{b}$. One hour after gavage and i.p. injection, all animals were given indomethacin $20 \mathrm{mg} / \mathrm{kg}$ (sc) and restrained for a further $3 \mathrm{~h}$. At the end of the study, animals were killed and the amount of macroscopic $\left(\mathrm{mm}^{2} / \mathrm{stomach}\right)$ damage determined. Data are presented as mean \pm s.e.m., ${ }^{*} P<0.001$ vs saline control.

\section{DISCUSSION}

Using a series of in vitro and in vivo models, we examined the effects of DMOG administration in stabilising gut mucosal integrity and stimulating repair. DMOG stimulated cell migration in an in vitro model of the early stages of wound repair, that is, restitution, and also increased proliferation. The time line for these effects were mirrored by increases in both HIF and the growth factor, VEGF. The importance of VEGF in these responses was further strengthened by the finding that the majority of the pro-migratory and proliferative activity was blocked if a VEGF neutralising antibody was present. We then progressed to an in vivo model and showed that DMOG administration reduced the amount of gastric injury and this effect was associated with a truncation of the indomethacin and restraint-induced fall in both HIF and VEGF levels. 




2

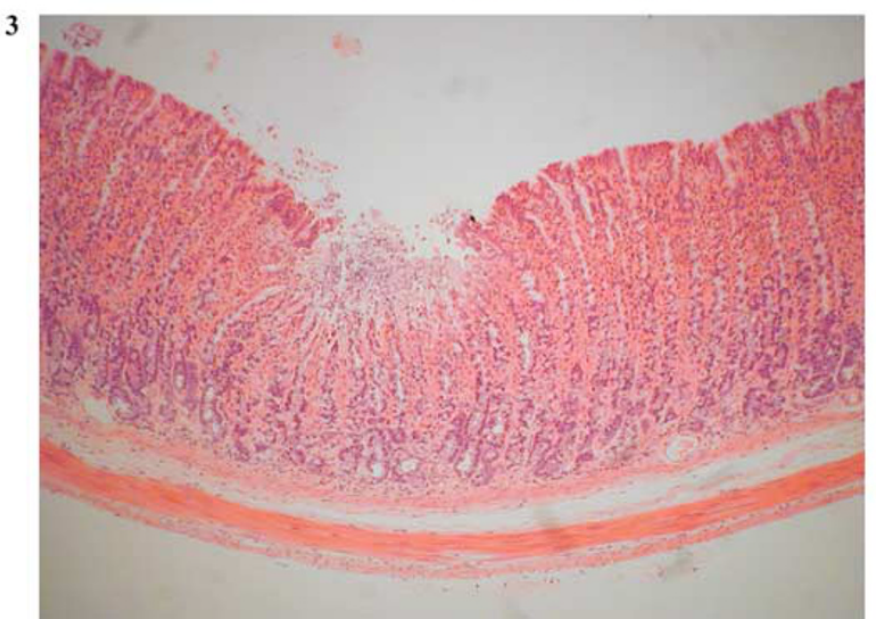

Figure 8 Representative stomach histology from experiment shown in Figure 7. (1) Normal stomach histology (rats did not receive indomethacin or restraint). (2) Extensive injury showing necrosis in animals that received indomethacin and restraint. (3) Animals that received DMOG before indomethacin and restraint had markedly reduced injury. Tissues were stained with haematoxylin and eosin. Original magnification $\times 40$.

For the in vitro studies, human gastric (AGS) and colonic (HT29) cells were used to examine the effects of DMOG on restitution, and cell proliferation as they provide robust reproducible models of human origin that we have experience of using for the study of growth factors, ${ }^{16,17}$ and other bioactive agents such as bovine colostrum. ${ }^{18}$ The use of both gastric and colonic cells supported the general applicability of our findings. Similarly, the in vivo studies examined the potential beneficial effect of DMOG on gastric (indomethacin and restraint-induced) damage in rats as NSAID's, such as indomethacin, continue to be a major cause of morbidity and mortality in humans. ${ }^{19,20}$ Caution always has to be shown, however, in extrapolating results obtained from in vitro cancer cell lines and animal models to the human situation.

Cell wounding monolayer assays are a well-established in vitro model of the early restitutive process that begins to occur within the first hour following injury. Our current studies showed a dose-dependent increase in movement in response to DMOG administration with most of the activity being dependent on the VEGF pathways. This process was not dependent on proliferation, as shown by lack of effect of adding mitomycin $\mathrm{C}$, and was also not inhibited by the addition of a TGF- $\beta$ neutralising antibody, a common pathway important in the restitutive activity of many growth factors. ${ }^{21}$ Incubating cells in hypoxic conditions stimulated their innate pro-migratory activity following wounding but, even under hypoxic conditions, the addition of DMOG stimulated the rate of migration further.

To further examine the mechanisms of these effects of DMOG, we performed an in vitro time course study. HIF and VEGF both increased slowly over time without the addition of DMOG, emphasising the importance of using an equivalent time point as a relevant control. Although highly reproducible, the reason behind this slow rise in HIF and VEGF is unclear but may reflect the fact that the cells are already a monolayer at time zero and will have local areas of hypoxia due to overgrowth of cells producing 'piling', which 

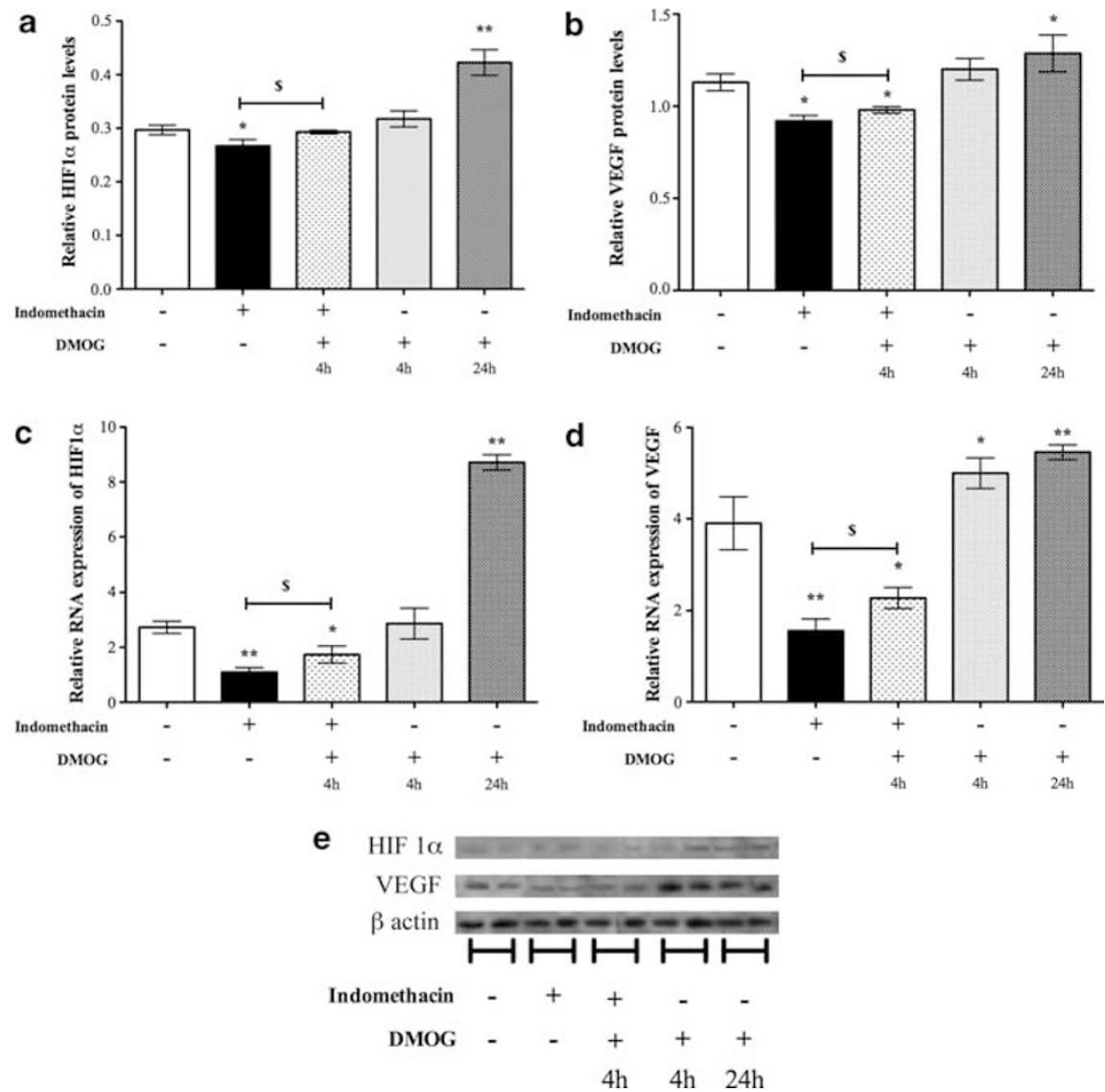

Figure 9 Effect of DMOG and/or indomethacin and restraint on HIF1 $\alpha$ and VEGF protein and mRNA expression levels in rat gastric damage model. Rat stomachs were examined to follow changes in $\operatorname{HIF}(\mathbf{a}, \mathbf{c})$ and $\operatorname{VEGF}(\mathbf{b}, \mathbf{d})$ levels over time after DMOG administration $(2.85 \mathrm{mmol}$, i.p.) in the presence or absence of indomethacin and restraint. For the 24-h post-DMOG exposure time point, there is no indomethacin/restraint group for ethical reasons. Protein levels are relative to $\beta$-actin loading control and mRNA levels were normalised to the housekeeping gene ( $\beta$-actin). (e) Representative western blots showing typical responses in HIF and VEGF protein levels under the various conditions (two per group).

will increase over time. For each time point studied, the co-presence of DMOG increased the amount of HIF and VEGF levels above the relevant control time point.

HIF is a heterodimeric basic-helix-loop-helix-PAS transcription factor consisting of HIF $1 \alpha$ and HIF $1 \beta$ subunits. The concentration of mature protein in the cell is regulated both at mRNA and at the post-translational level in response to hypoxia. ${ }^{22}$ One of the major control pathways is at the post-translational stage, mediated via the fact that HIF1 $\alpha$ is ubiquitinised under normoxic circumstances but this is prevented in hypoxic conditions, rapidly increasing intracellular levels. Our studies are in keeping with these findings, showing increases of both mRNA and protein levels in response to both hypoxia and DMOG administration.

Although restitution is helpful in re-establishing a continuous epithelial layer, stimulation of proliferation is required in the longer term. We used the well-validated method of DNA quantitation ${ }^{12}$ and showed administration of DMOG stimulated proliferation of AGS and HT29 cells. To further support these results, we also assessed proliferation using Alamar blue, ${ }^{13,14}$ which gave similar results. These results support and extend the findings of Dang $e t a^{23}$ who showed that disruption of HIF signalling resulted in reduced proliferation of various colonic cancer cell lines. Our studies further extended these findings by showing a high dependence of DMOG-induced proliferation on VEGF pathways.

Our in vivo studies demonstrated a beneficial effect of DMOG in indomethacin-induced gastric injury in rats. We chose this method as we have previously validated this model for various pro-healing agents, such as EGF. ${ }^{16}$ In the current study, we showed that gastric $\mathrm{pH}$ was not affected by DMOG administration, and DMOG can, therefore, be described as a cytoprotective agent. Indomethacin causes damage to the gastrointestinal tract by several mechanisms including reduction of mucosal prostaglandin levels, reduction of mucosal blood flow, stimulating neutrophil activation and possibly also stimulating apoptosis. ${ }^{20}$ Our studies showed a beneficial effect of DMOG when administered systemically or via gavage and in keeping with the results from the in vitro studies, administration of DMOG $4 \mathrm{~h}$ before killing truncated the reduction in tissue levels of HIF and VEGF caused by indomethacin. Although these changes were significant, they were relatively modest at the 4-h time point (although continued to increase over time). However, as both HIF and 
VEGF are produced and act locally, concentrations at the injured site may be relatively high. However, it is likely that several pathways are involved in the protective effects of DMOG and further work is required to examine this area in greater detail.

The importance of HIF expression in gut integrity is well demonstrated in two transgenic mice strains produced by Karhausen et $a l ;{ }^{24}$ increasing HIF expression (by mutating the VHL gene) increased resistance to tri-nitrobeneze sulphonic acid-induced colitis whereas the opposite effect was seen if HIF expression was prevented. The mechanism of action were unclear but the studies of Cummins et $a l^{6}$ that showed a potential benefit of DMOG in dextran sodium sulphate-induced colitis suggested that immune modulation mediated via HIF may be of particular importance.

In contrast to previous studies, our experiments focussed on the earliest stages of repair, namely restitution and proliferation. Although we demonstrated increased HIF levels, our in vitro studies emphasised the importance of VEGF in the protective effects of DMOG. VEGF monomer is a $23-\mathrm{kDa}$ peptide, the most abundant isoform is 165 amino acids long and known to stimulate angiogenesis and vasculogenesis. ${ }^{25}$

DMOG-stimulated migration occurred very rapidly in vitro (within $4 \mathrm{~h}$ ). This process may have relevance to our finding of a protective effect of DMOG in the in vivo model because re-establishment of a continuous epithelial layer is important to prevent secondary inflammation caused by luminal antigens. Our finding of a rapid beneficial effect of DMOG administration is of particular interest as previous studies using DMOG have used longer-term exposure of at least $24 \mathrm{~h}^{6}$ Although DMOG appears well tolerated, caution needs to be shown due to the fact that prolonged modification of $\mathrm{NF} \kappa \mathrm{B}$ levels may result in pro-tumourigenic effects ${ }^{6}$ and a short exposure has obvious advantages.

In summary, our studies suggest that DMOG and other relatively simple small molecules, which inhibit prolyl-4hydroxylase domain enzymes and/or influence VEGF levels, may be of value for the treatment of a variety of gastrointestinal disorders.

Supplementary Information accompanies the paper on the Laboratory Investigation website (http://www.laboratoryinvestigation.org)

\section{ACKNOWLEDGEMENTS}

This work was partially funded by the Wexham Park Gastrointestinal trust Grant number 2004/6772, a DDF/Belmont Trust Award and Cancer Research UK.

\section{DISCLOSURE/CONFLICT OF INTEREST}

Patrick Maxwell is a scientific founder, director and consultant for ReOx.

1. Ibrahim $C B$, Aroniadis $O C$, Brandt LJ. On the role of ischemia in the pathogenesis of IBD: a review. Inflamm Bowel Dis 2010;16:696-702.

2. Saraví FD, Cincunegui LM, Saldeña TA, et al. Indomethacin reduces short-circuit current and oxygen consumption in normal and chronically hypoxic rat colon. Acta Gastroenterol Latinoam 2006; 36:113-124.

3. Jaakkola P, Mole DR, Tian YM, et al. Targeting of HIF-alpha to the von Hippel-Lindau ubiquitylation complex by O2-regulated prolyl hydroxylation. Science 2001;292:468-472.

4. Takeda K, Cowan A, Fong GH. Essential role for prolyl hydroxylase domain protein 2 in oxygen homeostasis of the adult vascular system. Circulation 2007;116:774-781.

5. Bruick RK, McKnight SL. A conserved family of prolyl-4-hydroxylases that modify HIF. Science 2001;294:1337-1340.

6. Cummins EP, Seeballuck F, Keely SJ, et al. The hydroxylase inhibitor dimethyloxalylglycine is protective in a murine model of colitis. Gastroenterology 2008;134:156-165.

7. Nagel $S$, Papadakis $M$, Chen $R$, et al. Neuroprotection by dimethyloxalylglycine following permanent and transient focal cerebral ischemia in rats. J Cereb Blood Flow Metab 2011;31:132-143.

8. Rey S, Lee K, Wang CJ, et al. Synergistic effect of HIF-1alpha gene therapy and HIF-1-activated bone marrow-derived angiogenic cells in a mouse model of limb ischemia. Proc Natl Acad Sci USA 2009;106:20399-20404.

9. Lesslie DP, Summy JM, Parikh NU, et al. Vascular endothelial growth factor receptor-1 mediates migration of human colorectal carcinoma cells by activation of Src family kinases. $\mathrm{Br} J$ Cancer 2006;94:1710-1717.

10. Semenza GL. Hypoxia-inducible factor-1: control of oxygen homeostasis in health and disease. Pediatr Res 2001;49:614-617.

11. Playford RJ, Marchbank T, Chinery R, et al. Human spasmolytic polypeptide is a cytoprotective agent that stimulates cell migration. Gastroenterology 1995;108:108-116.

12. Jones $L$, Gray M, Yue ST, et al. Sensitive determination of cell number using the CyQUANT cell proliferation assay. J Immunol Methods 2001;254:85-98.

13. Marchbank T, Weaver G, Nilsen-Hamilton $M$, et al. Pancreatic secretory trypsin inhibitor is a major motogenic and protective factor in human breast milk. Am J Physiol Gastrointest Liver Physiol 2009;296: G697-G703.

14. Nakayama GR, Caton MC, Nova MP, et al. Assessment of the alamarBlue assay for cellular growth and viability in vitro. J Immunol 1997;204:205-208.

15. Marchbank $\mathrm{T}$, Boulton $\mathrm{R}$, Hansen $\mathrm{H}$, et al. Human transforming growth factor a (TGFa) is digested to a smaller (1-43), less biologically active, form in acidic gastric juice. Gut 2002;51:787-792.

16. Playford RJ, Marchbank T, Calnan DP, et al. Epidermal growth factor is digested to smaller, less active, forms in acidic gastric juice. Gastroenterology 1995;108:92-101.

17. Calnan DP, Westley $B R$, May $\mathrm{FE}_{\text {, }}$ et al. The trefoil peptide TFF1 inhibits the growth of the human gastric adenocarcinoma cell line AGS. J Pathol 1999;188:312-317.

18. Playford RJ, Floyd DN, Macdonald CE, et al. Bovine colostrum is a health food supplement which prevents NSAID induced gut damage. Gut 1999;44:653-658.

19. MacDonald TM, Morant SV, Robinson GC, et al. Association of upper gastrointestinal toxicity of non-steroidal anti-inflammatory drugs with continued exposure: cohort study. BMJ 1997;315: 1333-1337.

20. Levi S, Shaw Smith C. Non-steroidal anti-inflammatory drugs; how do they damage the gut? Br J Rheumatol 1994;33:605-612.

21. Dignass AU, Podolsky DK. Cytokine modulation of intestinal epithelial cell restitution: central role of transforming growth factor beta. Gastroenterology 1993;105:1323-1332.

22. Semenza GL. Regulation of mammalian $\mathrm{O}_{2}$ homeostasis by hypoxiainducible factor 1. Ann Rev Cell Dev Biol 1999;15:551-578.

23. Dang DT, Chen F, Gardner LB, et al. Hypoxia-inducible factor-1alpha promotes nonhypoxia-mediated proliferation in colon cancer cells and xenografts. Cancer Res 2006;66:1684-1693.

24. Karhausen J, Furuta GT, Tomaszewski JE, et al. Epithelial hypoxiainducible factor- 1 is protective in murine experimental colitis. J Clin Invest 2004;114:1098-1106.

25. Leung DW, Cachianes G, Kuang WJ, et al. Vascular endothelial growth factor is a secreted angiogenic mitogen. Science 1989;246: 1306-1309. 